
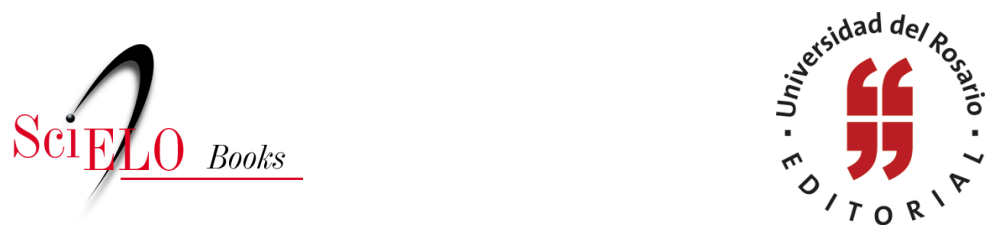

\title{
Consideraciones para la política cultural en la Universidad del Rosario
}

Adriana Díaz Támara

Margarita Guzmán Bejarano

\section{SciELO Books / SciELO Livros / SciELO Libros}

DÍAZ TÁMARA, A., and GUZMÁN BEJARANO, M.

Consideraciones para la política cultural en la Universidad del Rosario. In: DÍAZ TÁMARA, A., and GUZMÁN BEJARANO, M., eds. Proceso de construcción de la política cultural en la Universidad del Rosario [online]. Bogotá: Editorial Universidad del Rosario, Decanatura del Medio Universitario, 2014, pp. 87-92. ISBN: 978-958-738541-0. https://doi.org/10.7476/9789587385410.0005.

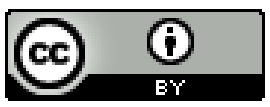

All the contents of this work, except where otherwise noted, is licensed under a Creative Commons Attribution 4.0 International license.

Todo o conteúdo deste trabalho, exceto quando houver ressalva, é publicado sob a licença Creative Commons Atribição 4.0.

Todo el contenido de esta obra, excepto donde se indique lo contrario, está bajo licencia de la licencia Creative Commons Reconocimento 4.0. 


\section{Consideraciones para la política cultural en la Universidad del Rosario}

Adriana Díaz Támara

Margarita Guzmán Bejarano

En el estudio que se llevó a cabo entre el 2009 y 2011, dentro del marco conceptual que se estableció partiendo de unas estrategias participativas y consensuadas en la Universidad del Rosario, se llegó a las siguientes consideraciones para la construcción de una política cultural en la Universidad.

La política cultural se entenderá como un marco general que moviliza diferentes actores, así como valores y comportamientos diversos, conocimientos e instrumentos variados, con miras a desarrollar y fortalecer conjuntos de prácticas de individuos y grupos sociales sin distinción. Dicha política busca vincular y orientar las actividades culturales desarrolladas desde la Universidad para que a través de ellas se divulgue y conserve el campo cultural universitario, contribuyendo así a la transformación indispensable para el desarrollo de la sociedad. Igualmente, teniendo en cuenta una de las funciones sustantivas de la universidad, la investigación en el campo cultural ocupa un espacio fundamental para la protección, promoción e impulso de la cultura en general.

La política cultural se fundamenta en los siguientes principios: transversalidad, integralidad, universalidad y salvaguarda.

La transversalidad implica que la cultura estará articulada a todo el ejercicio docente, investigativo, de extensión y administrativo en todas las áreas, programas y unidades de 
la Universidad; la integralidad de la cultura hace referencia a todos los aspectos de la persona humana, como ser racional y social, sus aspectos espirituales, intelectuales y físicos; la universalidad implica que deberá cobijar toda actividad cultural desarrollada por la comunidad universitaria, entendida esta dentro de la pluralidad y la democracia, contemplando la diversidad, la interculturalidad, con inclusión e integración; el principio de salvaguarda busca garantizar la permanencia de la cultura y el patrimonio por medio de la conservación y divulgación de todas las actividades culturales en los campos de creación, producción, circulación, acceso y consumo.

La política cultural de la Universidad estará orientada a la consecución de los siguientes objetivos para el desarrollo de las acciones culturales:

- Contribuir a una formación integral fortaleciendo el componente cultural como factor generador de riqueza social.

- Crear el marco general que oriente la planeación, gestión, infraestructura y financiación de todas las acciones culturales que se desarrollen en la Universidad.

- Reconocer las prácticas artísticas y expresiones culturales como componente fundamental del medio universitario complementario del currículo.

- Implementar estrategias para transformar positivamente actitudes, hábitos, tendencias y percepciones dentro del entorno de la comunidad universitaria.

- Activar mecanismos e incentivos para fortalecer los conocimientos y prácticas participativas en lo cultural al interior de la Universidad, así como fomentar el acceso frecuente al arte y a otras expresiones culturales en la comunidad universitaria. 
- Aumentar el conocimiento, la práctica y continuidad de los valores fundamentales de la Universidad del Rosario.

- Investigar sobre la apropiación del arte y la cultura de la comunidad rosarista y el impacto de programas y proyectos de consumo cultural.

- Integrar y articular los procesos culturales institucionales con el fin de lograr el aprovechamiento y fortalecimiento de la participación en las dinámicas culturales de la sociedad y del entorno.

- Visibilizar las acciones culturales que se desarrollan al interior de la Universidad.

- Crear las condiciones para fortalecer la cultura rosarista a través del estímulo a la creatividad y a las prácticas artísticas, y del fomento y conservación de las expresiones culturales y del patrimonio.

- Fomentar la circulación del patrimonio cultural de la Universidad del Rosario.

- Introducir lo simbólico como criterio para el diseño, construcción e intervención de las sedes de la Universidad.

La Universidad del Rosario está desarrollando unas acciones conducentes a la construcción, consolidación y fortalecimiento de planes, programas y proyectos culturales que estén orientados a la creación de redes culturales con el fin de promover la formación de públicos de consumo cultural. Igualmente, busca el fortalecimiento de valores y sentido de pertenencia en la creación de una comunidad académica comprometida con lo cultural e implementa la preservación y la promoción de la cultura en la institución. 
$\mathrm{Al}$ ser acción cultural transversal a todas las unidades académicas y administrativas de la Universidad, los objetivos de la política cultural se desarrollan a través de los siguientes programas:

- Fortalecimiento de la cultura e identidad rosarista

- Vive la Cultura Universitaria

- Extensión Cultural

\begin{tabular}{|c|c|}
\hline PROGRAMAS & PROYECTOS \\
\hline $\begin{array}{l}\text { Fortalecimiento de } \\
\text { la cultura rosarista }\end{array}$ & $\begin{array}{l}\text { - Proyecto: La representación y lo simbólico en el } \\
\text { Rosario } \\
\text { - Proyecto: Cultura y participación } \\
\text { - Proyecto: Formación en valores } \\
\text { - Proyecto: Circulación y divulgación del patrimonio } \\
\text { cultural } \\
\text { - Proyecto: Claustro Virtual en Second Life } \\
\text { - Proyecto: Formación y valoración en patrimonio } \\
\text { cultural }\end{array}$ \\
\hline $\begin{array}{l}\text { Vive la Cultura } \\
\text { Universitaria }\end{array}$ & $\begin{array}{l}\text { - Proyecto de apoyo a las prácticas artísticas y cultu- } \\
\text { rales } \\
\text { - Proyecto de comunicación e información en arte y } \\
\text { cultura } \\
\text { - Proyecto de Interculturalidad }\end{array}$ \\
\hline Extensión Cultural & $\begin{array}{l}\text { - Proyecto: Territorio y patrimonio } \\
\text { - Proyecto: Arte y ciudad } \\
\text { - Proyecto: Diversidad e interculturalidad local } \\
\text { - Proyecto de Gestión Cultural }\end{array}$ \\
\hline
\end{tabular}

\section{Programa Fortalecimiento de la Cultura e Identidad Rosarista}

Este programa busca fortalecer la apropiación de aquellos componentes que definen la cultura en la Universidad del Rosario y de las percepciones, prácticas y estilos de vida que los sustentan, tales como: la historia de la Universidad, la estructura de su sistema de participación, la relación entre docentes y estudiantes, 
los valores que definen el perfil y lo que significa ser rosarista. Igualmente, busca crear condiciones y estrategias para alcanzar la apropiación social del patrimonio cultural de la Universidad del Rosario por medio de la activación del patrimonio desde los conceptos de la museología y la museografía, vinculando en forma participativa a la comunidad. Este programa incluye la valoración y el conocimiento del patrimonio cultural del Rosario desde la academia.

\section{Programa Vive la Cultura Universitaria}

Este programa pretende estimular y desarrollar la creatividad de las personas y colectivos a partir de las prácticas asociadas a la creación, formación y circulación del arte y de las expresiones culturales. Igualmente, busca promover la comunicación y la información del arte y la cultura que se desarrolla en la Universidad, en la ciudad y en el país e integra estudios y mediciones sobre consumo cultural.

El programa Vive la Cultura Universitaria incluye también el proyecto de interculturalidad, el cual busca fomentar la interculturalidad, a nivel nacional e internacional, en función de integrar los temas culturales con el aprendizaje, la investigación y el trabajo cotidiano de la Universidad.

\section{Programa de Extensión Cultural}

Para la Universidad del Rosario:

La función de Extensión hace referencia a los procesos y actividades a través de los cuales la Universidad interactúa con su entorno nacional e internacional en el cumplimiento de su función social, como organización del conocimiento, contribuyendo a integrar la teoría con la práctica, la exten- 
sión con las otras funciones universitarias y el entorno con la institución misma. ${ }^{1}$

El programa de extensión cultural ha pretendido desarrollar proyectos relacionados con la articulación de temas de arte y patrimonio, territorio y ciudad dentro de la interculturalidad y la diversidad en gestión cultural. Dichos proyectos buscan articular iniciativas culturales del entorno en los circuitos de producción y circulación, así como fomentar el diálogo y la visibilización de la cultura y su diversidad como fin en procesos de desarrollo y así mismo ofrecer capacitación en gestión cultural.

1 Definición Extensión, Decreto Rectoral 1011 de 2008 - Política de Extensión. 